\title{
SilenCiO Y CONTEMPLACIÓN: RASGOS DE LO MÍSTICO EN LA POESÍA DE Jorge CADAvid*
}

\author{
Silence and Contemplation: Traits of \\ Mysticism in Jorge Cadavid's Poetry
}

Daniel Clavijo Tavera ${ }^{1}$

\footnotetext{
* Artículo derivado del proyecto de investigación "Del canon a las márgenes: revisión crítica de la poesía colombiana en el siglo xx", que hace parte del Grupo de Investigación Estudios en Filosofía, Hermenéutica y Narrativas, del Departamento de Humanidades de la Universidad Eafit (Medellín, Colombia). El proyecto es financiado por la Universidad Eafit.

Cómo citar este artículo: Clavijo Tavera, D. (2021). Silencio y contemplación: rasgos de lo místico en la poesía de Jorge Cadavid. Estudios de Literatura Colombiana 48, pp. 191-207. DOI: https://doi.org/10.17533/udea.elc.n48a12

1 https://orcid.org/0000-0003-4266-3681 oclavijo@eafit.edu.co

Universidad Eafit, Colombia
}

Editores: Andrés Vergara Aguirre, Christian Benavides Martínez, Valentina Noreña Gómez

Recibido: 14.08 .2020

Aprobado: 26.10.2020

Publicado: 18.12 .2020

Copyright: (2021 Estudios de Literatura Colombiana. Este es un artículo de acceso abierto distribuido bajo los términos de la Licencia Creative Commons AtribuciónNo comercial - Compartir igual 4.0 Internacional
Resumen: A partir de los rasgos que permiten una delimitación de la idea de lo místico, este artículo indaga en la estrecha relación entre lenguaje poético y mística en la obra del poeta Jorge Cadavid. Tras una revisión de los aportes teóricos de diversos autores a la caracterización del concepto de mística, se emprende el análisis de los poemas de Cadavid a la luz de las nociones de silencio - tanto en las posibilidades de tematización como en los mecanismos retóricos y de enunciación por los cuales el silencio ingresa en el poema-y de contemplación, entendida como la mirada atenta.

Palabras clave: Jorge Cadavid; mística; poesía; silencio; contemplación.

Abstract: Starting from the aspects that allow a delimitation of the idea of the mystical, this article inquires into the close relationship between poetic language and transcendent experience in the work of the poet Jorge Cadavid. Following a review of several authors' theoretical contributions to the definition of mysticism, Cadavid's poems analysis is undertaken in light of the concepts of silence - both in the possibilities of theming and in the rhetorical and enunciation mechanisms through which silence enters the poem- and contemplation, understood as the attentive look.

Key words: Jorge Cadavid; mysticism; poetry; silence; contemplation. 


\section{Introducción}

Participación conjunta del misterio, posibilidad de sobrepasar los alcances del conocimiento racional y del lenguaje discursivo, así como enajenación del sujeto, "en la desposesión del yo personal", son algunos de los puntos de encuentro que destacaba el poeta Emilio Sosa López (1954) para describir la estrecha relación entre poesía y mística. A estos podrían sumarse rasgos propios del lenguaje de ambos campos, como el silencio y la primacía de la imagen, para analizar la manera en que el poema dialoga con las particularidades de la experiencia trascendente. Justamente, este texto pretende indagar en la relación entre poesía y mística, a partir del análisis de los fenómenos del silencio y la contemplación en la obra poética de Jorge Cadavid, ${ }^{1}$ donde la ausencia de palabras — que es espacio significativo—y la mirada atenta se configuran como espacios que revelan comunión con la totalidad.

En efecto, es en este último punto en el que convergen diferentes perspectivas al tratar de delimitar la inestable, polivalente y compleja noción de mística, para la que resulta inadecuado un abordaje esencialista que desatienda las condiciones específicas de los sistemas en que se experimenta (Velasco, 2003, p. 22). La idea de una experiencia interior e inmediata, en la que el sujeto se une, se funde, con la divinidad y alcanza una presencia trascendente en la vida humana -idea presente en visiones canónicas de la teorización mística como las de William James (1994), Evelyn Underhill (2006), Bernard McGinn (citado por Velasco, 2003), Emilio Sosa López (1954), y en otras como la fenomenología de Juan Martín Velasco (2003) o Carlos Miguel Gómez Rincón (2015)_, permite de alguna manera una generalización operativa del término para establecer ciertos encuentros entre el lenguaje poético y la reflexión sobre la experiencia mística. Velasco (2003) se acerca a una definición global del concepto en los siguientes términos:

[...] experiencias interiores, inmediatas, fruitivas, que tienen lugar en un nivel de conciencia que supera la que rige en la experiencia ordinaria y objetiva, de la unión - cualquiera que sea la forma en la que se viva - del fondo del sujeto con el todo, el universo, el absoluto, lo divino, Dios o el Espíritu (p. 23).

Entre los libros de poemas publicados por Cadavid se encuentran: Diario del entomólogo (1998/2003), La nada (2000), Un leve mandamiento (2002), El vuelo inmóvil (2004), El derviche y otros poemas (2006), Herbarium (2007), Tratado de cielo para jóvenes poetas (2008), Heráclito inasible (2010), Los ojos deseados (2011), El bosque desnudo (2013) y Pequeña historia de la fotografía (2015). Entre su producción ensayística, relacionada particularmente con el contenido de las reflexiones de este texto, se pueden mencionar el libro Escribir el silencio. Ensayos sobre poesía y mística (2013) y los textos "El lenguaje de la poesía. Entre la analogía y el refrenamiento" (2009) y "La poesía silente" (2016). 
Cabe aclarar que para algunos autores la diversidad de manifestaciones y tradiciones emparentadas con lo místico abarca posibilidades que traspasan el ámbito de lo religioso. En este sentido, el término "místico" es empleado para dar cuenta de espacios límite de la experiencia humana. Tanto David Le Breton (2016) como Velasco (2003) hablan de una mística profana, presente en campos como el de la filosofía - asombro, admiración, angustia, entre otros - o alcanzable, por ejemplo, mediante el uso de sustancias alucinógenas o en situaciones que rompen con la cotidianidad, como la reclusión, la enfermedad, la soledad o la convalecencia (Velasco, 2003, p. 102).

Frente a la dificultad de adecuar una definición única del concepto, es frecuente que "lo místico" se aborde a partir de caracterizaciones o de la identificación de rasgos comunes - también cambiantes, entendidos de diversas maneras por las diferentes tradiciones e históricamente condicionados (Gómez Rincón, 2015, p. 11)—. Frente a las características esenciales de la mística señaladas por James (1994) a comienzos del siglo xx, entre las que se encuentran la inefabilidad, la cualidad de conocimiento, la transitoriedad y la pasividad (pp. 179-180), Underhill (2006) agrega el carácter activo y práctico, los objetivos espirituales y trascendentales de la experiencia mística, la orientación hacia el Uno como objeto de amor, y la unión con el Uno como estado definitivo (p. 99). Gómez Rincón (2015), por su parte, en línea con planteamientos de estos dos autores clásicos, describe la mística como una experiencia fundamentada también por el carácter noético y la inefabilidad, así como por el sentido de realidad absoluta (p. 11). Y es, precisamente, en estas características donde aparecen nociones como las de silencio y contemplación, autoabandono, disolución del yo o la conciliación de los opuestos como rasgos propios de la expresión de lo trascendente, presentes también en la palabra poética.

En el caso particular de la poesía de Jorge Cadavid, donde son claramente perceptibles todos estos rasgos, podría hablarse de una especie de sensibilidad colindante con una mística sin doctrina, pues el propio poeta se ha definido como portador de un agnosticismo "deplorable" que le ha permitido explorar "algunos estados alterados de conciencia, epifanías que me abrieron como en una oración otras formas de percepción inéditas en mí" (Cadavid, 2013, p. 7). ${ }^{2}$ De hecho, sus libros albergan, in- 
distintamente, alusiones a diversas tradiciones religiosas, entre las que se encuentran la cristiana, la judía, la sufí — con dedicatorias y referencias explícitas a la obra de místicos como el maestro Eckhart, Maimónides o Miguel de Molinos-, así como la mencionada mística profana. Al final, los versos de Cadavid tratan de entender el ejercicio poético como revelación, como totalidad, sin condicionamientos dogmáticos, como lo afirma en su ensayo "El lenguaje de la poesía. Entre la analogía y el refrenamiento", al referirse al misterio que se oculta tanto en la palabra poética como en la experiencia trascendente: "Toda actividad poética tiene un sentido religioso, porque siempre apunta a la Totalidad" (Cadavid, 2009, p. 94).

\section{La experiencia del silencio}

Desde su etimología, el término "mística" está emparentado con la idea de silencio, así como con las nociones de secreto, misterio u ocultamiento, en tanto proviene del verbo griego myein, que significa cerrar la boca (Soto Posada, 2013, p. 7). En una perspectiva general, son principalmente tres los ámbitos del silencio convocados en la experiencia mística (Toro Murillo y Clavijo Tavera, 2020, p. 283): de un lado, podría hablarse de una especie de disposición a la escucha en que entra todo místico para despojarse del ruido del mundo y permitir la presencia de la divinidad; de otro, el silencio de los iniciados y, por último, la inefabilidad, es decir, por la incapacidad del lenguaje discursivo para dar cuenta de ella. El silencio aparece entonces como respuesta posible - $\mathrm{O}$ única - frente a lo trascendente. De hecho, la escritura mística parte en sí misma de una paradoja: la necesidad de expresar algo que reconoce, de antemano, inexpresable.

Así como la experiencia mística, el silencio se encuentra estrechamente vinculado con la palabra poética, en la medida en que se despliega en la tensión existente entre la palabra discursiva y su negación: el lenguaje poético trasciende el significado lógico-objetivo de la referenciación discursiva y revela un nuevo sentido, a partir, justamente, de la negación de dicho significado objetivo (Villoro, 2016, p. 61). Tanto en su obra ensayística como poética, Jorge Cadavid (2016) se ha aproximado explícita e implícitamente a este vínculo. De un lado, afirma que, como lenguaje alusivo, "lleno de elipsis y paradojas,

dan cuenta de experiencias que sobrepasan la percepción puramente racional. En la misma línea se inscribía Underhill (2006) al anotar que no es místico todo aquel que cuente con ciertas intuiciones parciales y artísticas de la realidad: "El verdadero místico es una persona en la que esas facultades trascienden la etapa meramente artística y visionaria y se elevan hasta la altura de la genialidad, en las que la conciencia trascendental puede dominar la conciencia normal, y que se ha entregado decididamente al abrazo de la Realidad" (p. 93). 
de oxímoron y balbuceos, preñado de ausencias", la poesía es el género más cercano al verdadero silencio (p. 236). De otro, en sus poemarios, el silencio o bien se tematiza, o bien se escribe desde él: la brevedad, la supresión de elementos retóricos o el predominio de las imágenes no transmiten únicamente la sensación visual de la ausencia de sonido, sino que, como lo indica Guillermo Martínez (2002), remiten a un silencio trascendente (p. 13). ${ }^{3}$ Así, la experiencia empírica del silencio, que alberga siempre un excedente de sentido, es trasladada a la página para convertirse en objeto de análisis.

La tematización del silencio en Cadavid es evidente desde los títulos mismos de los poemarios, de los capítulos y de los poemas que aluden específicamente a lo que Ramón Pérez (2013) denomina los tópicos asociados al silencio (p. 34). Así, aparecen en forma recurrente en estos elementos paratextuales de la obra del poeta palabras-imágenes como "nada", "sombra”, “vacío", "luz”, "blanco”, "alma”, "soledad”, "secreto" o "meditación”, por nombrar algunas, que claramente remiten a una ausencia sonora. Dentro de estas evocaciones, cabe mencionar el nombre del segundo apartado del libro Un leve mandamiento (2002), titulado "Wittgenstein en Amherst", nombre propio - el primero- que se vincula directamente con estas isotopías en la medida en que fue Wittgenstein (2013) quien formuló esa especie de imperativo ético sobre el silencio: "lo que en cualquier caso puede decirse, puede decirse claramente; y de lo que no se puede hablar, hay que callar la boca" (p. 103).

Justamente, en línea con la referencia explícita a la primacía del silencio frente a la imposibilidad de la lengua de acceder a ciertas realidades - "aquello de lo que no se puede hablar"-, entre ellas la profundidad del pensamiento, se encuentran poemas como "Charla con nubes":

\section{Charla con nubes}

No hay modo de conocer

la lengua de una nube

¿No será el silencio el que hable

por el blanco?

¿No serán nubes

mis pensamientos? (Cadavid, 2008, p. 65).

Desde el título mismo, el poema se construye sobre el campo semántico del diálogo: vocablos como "charla", "lengua" o el verbo "hablar" remiten directamente a la inte-

3 Pérez (2013) señala que es posible distinguir entre "hablar del silencio" y "hablar desde el silencio"; en este segundo caso, independientemente del tema tratado, el lenguaje se construye desde una estética del silencio en la que aparecen recursos como los mencionados (p. 26). 
racción comunicativa guiada por la palabra. Sin embargo, la negación inicial sugiere ya en el primer verso que dichas expresiones sean asumidas más allá de su alcance discursivo; la charla silenciosa que se entabla con la nube-pensamiento no se daría en el plano de la funcionalidad de la comunicación, sino en la totalidad de la compenetración. Solo el silencio puede "hablar por" esa nada, ese vacío, ese blanco donde el pensamiento se desdibuja de su carácter netamente conceptual y se presenta en lo etéreo e inaprehensible de la nube: "Toda la experiencia sensible tiene la forma de las nubes", dirá Cadavid en el prefacio del poemario El bosque desnudo (2013). De hecho, como indica Marcela Labraña (2017), la nube, en tanto imagen de lo indeterminado, ha sido parte de la retórica de lo irrepresentable, como "signo de lo sagrado" (pp. 42-43).

La trascendencia que asumen los términos mencionados se deriva también de la estructura enunciativa del poema: la negación inicial es cuestionada, a su vez, con las dos preguntas siguientes — construidas también desde la negación-, en un entramado que sugiere la reflexión sobre el carácter epistemológico de aquello que se ubica más allá de las posibilidades del concepto. Si bien no hay modo de conocer la lengua de la nube, es posible que el silencio trace una vía para dicho conocimiento, y es posible, asimismo, que aquello que tradicionalmente se ha limitado al ámbito de lo racional-discursivo - “mis pensamientos”- en su grado más profundo pueda ser alcanzado —únicamente- por el silencio. La imposibilidad de la palabra es la mejor prueba de la profundidad del sentimiento, dice Le Breton (2016, p. 155).

En línea con las posibilidades del silencio en esa profundidad donde el pensamiento es ya nube se encuentran poemas que aluden a cierta imagen de un vaciamiento interior que permite la apertura de espacios de compenetración. Así pueden leerse poemas como "Intemperie" o "Noticia del maestro Eckhart":

\author{
Intemperie \\ Una voz vertical \\ y un silencio horizontal \\ Apenas dos coordenadas \\ en el aire \\ y un espacio vacío \\ por el cual desplazarse (Cadavid, 2004, p. 34).
}

\section{Noticia del maestro Eckhart}

Tiendo un arco

por encima del pensamiento

elevo una oración vertical 


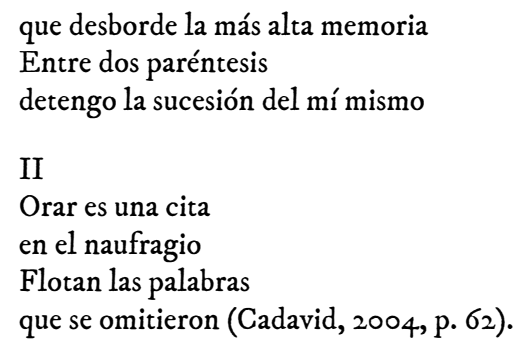

La tradición de la mística cristiana —en autores como Dionisio Areopagita, San Juan de la Cruz o el propio maestro Eckhart- entiende la purificación, la iluminación y la perfección como etapas del proceso de encuentro con la divinidad, donde la oración juega un papel primordial como mecanismo de liberación y despojo de lo accesorio en el camino hacia la interioridad (Le Breton, 2016, p. 158). En ese sentido, la verticalidad de "Intemperie" y de "Noticia del maestro Eckhart" — mucho más explícita en este segundo caso- supera en ambos textos la tradicional concepción de la oración como una conversación con la divinidad para ocuparse también del vaciamiento de quien dispone un espacio para experimentar la presencia trascendente.

Prescindiendo del empleo de verbos, "Intemperie" aborda el mencionado proceso a partir de la imagen de una especie de encuentro que traza las dos direcciones en las que convergen la voz vertical inicial y el silencio horizontal sobre el que esta se posaría. El título del poema remite tanto a una disparidad temporal — que se resolvería en la integración propuesta por el cruce de direcciones- como a una apertura que se extiende infinitamente al configurar la escena donde se encuentran el aire y el espacio vacío. La única acción del poema está evocada por la posibilidad que sugiere ese "desplazarse" final —acción no conjugada— que permitiría pensar en el movimiento de una suerte de presencia reflexiva e impersonal —se- a través de ese vacío. "El vacío es el viaje”, dirá el propio Cadavid (2013) en un poema posterior, en una imagen que integra presencia y espacio, movimiento y quietud (p. 55).

"Noticia del maestro Eckhart", por su parte, describe el mismo proceso mediante el recurso del paréntesis, que no elimina, sino que suspende, que sugiere la latencia de las presencias, para llegar a esa detención de la "sucesión del mí mismo", que no es otra cosa que la pausa de la temporalidad del yo que se integra ahora a la de la realidad trascendente. La segunda parte del poema se instala como una especie de aclaración del fenómeno verbal que ocurre en la oración: un encuentro posible gracias al fracaso del 
lenguaje. Esta estructura vacío-oración es replicada en el poema "El rabino Seb Tom", que sigue a "Noticia del maestro Eckhart" en El vuelo inmóvil (2004), justamente en el capítulo dedicado a "los divinos estrategas", donde el vaciamiento permite una especie de transmutación y posterior fusión con la divinidad; el título del poema indica el sujeto sobre el que recae el reflexivo "se" que, vuelto hacia sí mismo, se deifica: "Se inclina para orar / hacia sí mismo / va haciéndose un dios / desde su borde” (Cadavid, 2004, p. 63). ${ }^{4}$

$\mathrm{Si}$, como indica Velasco (2003), en la tradición mística cristiana son recurrentes los superlativos o interjecciones grandilocuentes como “¡oh!” o “icuán!” (p. 53), los versos de Cadavid toman distancia de dichos modos de locución para insertar, en cambio, imágenes sutiles y mudas que más que a la pretensión de dar cuenta de la experiencia mística individual, adscrita a una tradición, remiten a una conciencia trascendente del instante. También se aleja Cadavid del lenguaje autoimplicativo de la primera persona que caracteriza ciertas tradiciones del lenguaje místico (Velasco, 2003, p. 57) y propone, en la mayoría de sus poemas, una supresión del yo hablante para dar espacio a la voz contemplativa que, desde el silencio, describe imágenes silenciosas. Ocurre así en "Cartuja": "La nieve cae / en el papel blanco / La imagen asoma / como un gran silencio" (Cadavid, 2010, p. 25). El silencio del poeta, decía Emilio Sosa López (1954), "es una forma de integración espiritual de la vida en la obra” (p. 13), integración que en Cadavid ocurre también con la mirada atenta, "la mirada silente", como titula uno de sus poemas.

\section{La contemplación: observar el (en) silencio}

Afirma Michel de Certeau (2006) que la aparición de la mística está estrechamente relacionada con la concentración de los debates alrededor de la idea de "ver", modificación antropológica que tuvo lugar durante la transición entre la Edad Media y el Renacimiento:

La visión sustituye paulatinamente al tacto o a la audición. Transforma la propia práctica del saber y de los signos. También el ámbito religioso se reorganiza en función de la oposición entre lo visible y lo invisible, de modo que las experiencias 'ocultas', muy pronto agrupadas bajo el nombre de 'mística', adquieren una pertinencia que no tenían (p. 9 ๑).

$4 \quad$ Las dos partes del poema "El rabino Seb Tom”, del libro El vuelo inmóvil (2004), integran dos poemas independientes del libro Un leve mandamiento (2002); estos poemas son "Vacío", que se convierte en la primera parte, $y$ "El hombre", que pasa a ser la segunda parte, donde el genérico "hombre" toma el lugar de aquel que ora y, por consiguiente, se integra con la divinidad. 
Del latín contemplari, en su acepción más general, el término "contemplar" se relaciona con "mirar atentamente" (Corominas, 1987, p. 168). Con esa breve definición podría describirse el elemento transversal a toda la obra poética de Jorge Cadavid: la mirada consciente, reflexiva, silenciosa. De hecho, tal como se anotó arriba con relación a los términos vinculados con el campo semántico del silencio, ocurre lo mismo -y en un grado aun mayor - con las palabras que remiten a la isotopía de la visión. Así, en sus títulos y poemas son recurrentes conceptos-imágenes como "ojos", "fotografia", "contemplación", "mirada”, "lo visible", "espejo", "luz”, entre otros. Incluso, uno de sus poemarios se titula Los ojos deseados (2011) — como el verso de San Juan de la Cruz-, e incluye como prólogo el texto "Estudio sobre la mirada", ${ }^{6}$ del propio Cadavid (2011), que califica los poemas del libro como descripciones del tránsito entre el concepto y el recorrido del ojo, como "ese espacio donde es posible ver, verse y ser visto" (p. 5).

Decía Walter Ong (2009) que, en oposición a la integración que genera el oído, la vista divide (p. 76), afirmación que se desvirtúa en los poemas de Cadavid, donde la mirada aspira a tal nivel de atención que se ve envuelta en experiencias de enajenación y extrañamiento que revelan la totalidad que subyace a las formas de lo sensorialmente perceptible o que, en ocasiones, termina por integrar lo contemplado y a quien contempla en una misma imagen, paradójica e infinita. La develación de la singularidad de lo cotidiano ocurre en poemas como "Revelado I", que abre el poemario Pequeña bistoria de la fotografía (2015), homónimo del ensayo de Walter Benjamin (1931):

\author{
Revelado I \\ Los acontecimientos singulares \\ no son raros \\ ocurren en todas partes \\ a cada momento \\ en todas las escalas \\ Basta un descuido \\ para que todo se revele \\ basta limpiar los ojos \\ para que aquello que no sabes aparezca (Cadavid, 2015, p. 13).
}

$5 \quad$ “Oh cristalina fuente, / si en esos tus semblantes plateados / formases de repente / los ojos deseados / que tengo en mis entrañas dibujados” (De la Cruz, 2010, p. 56). El poeta José Ángel Valente (2000) ve en esa estrofa de San Juan de la Cruz una de las manifestaciones más claras de la "infinita perpetuación del deseo" de la perspectiva mística (p. 201). Esa apertura hacia el infinito, desde la mirada, como se verá más adelante, es una de las imágenes más recurrentes en la poesía de Cadavid.

6 Este también es el nombre de uno de los poemas que integran el libro Heráclito inasible (2010). 
Lejos de una idea grandilocuente de lo extraordinario, el poema sugiere que su presencia es permanente: lo singular está ahí, es la mirada ordinaria la que no se ha adecuado para vislumbrarlo. En "Revelado I", dicha adecuación se soporta sobre una inversión: en lugar de requerir atención excesiva, es necesario un descuido; es decir, una des-atención, un olvido de la superficialidad que normalmente oculta la posibilidad de acceder a ese "todo", a esa totalidad que se revela. En este sentido, la mirada es, más allá de lo perceptivo, una disposición de apertura que implica "limpiar los ojos" para ver lo desconocido en lo conocido, para acceder al misterio de lo cotidiano.

Además de penetrar en lo oculto que "ocurre en todas partes", la mirada atenta del poeta permite, en ocasiones, desmontar el engaño de la abstracción —que, así como para la imagen, aplicaría también para el lenguaje verbal一, como ocurre en el poema "Proposiciones". El verso "Evita las simetrías", en el tono imperativo, seguido de la alusión a Dios como creador, no es otra cosa que el reconocimiento de la imposibilidad del lenguaje conceptual — aquí geometría一, que ha influido hasta en la imagen, de acceder a la profundidad, a la esencia de las cosas.

\section{Proposiciones \\ Una gota no es una esfera \\ Una montaña no es una parábola \\ Un insecto no es un punto \\ Un rayo no es una línea \\ El caos opera con todas las escalas simultáneamente \\ No confundas indefinido con infinito \\ Evita las simetrías \\ Dios no es geómetra (Cadavid, 2000, p. $6_{3}$ ).}

Tanto en "Revelado I" como en "Proposiciones" se presenta una reflexión general sobre la mirada, idea que se materializa a lo largo de toda la obra poética de Cadavid con la visión puesta, en particular, sobre el transcurrir del instante en la naturaleza. Es así como insectos, plantas, frutas, nubes, aves o espacios cotidianos, entre tantas otras imágenes, se convierten en objetos de una contemplación exterior que alberga siempre la conciencia sobre la mirada interior de quien observa; una mirada preexistente, incesante, que subyace a la contingencia del momento de la visión exterior. Como decía Sosa López (1954), "En la percepción de esa unidad anterior a la inmensidad del tiempo y del espacio, el poeta alcanza la quietud” (p. 19), entendiendo por quietud —como se verá más adelante— la aspiración última, la visión integrada del tiempo, 
la eternidad. El despliegue infinito de esta "visión" es descrito en poemas como "El perplejo", donde la mirada interior — plasmada en el ojo cerrado— se re-une con la mirada precedente y posterior.

\author{
El perplejo \\ La visión del ojo cerrado es única \\ Dura antes de su comienzo \\ Se extiende después de su fin (Cadavid, 2004, p. 43).
}

Esta reflexión plantea otra de las constantes en la creación poética de Cadavid, mencionada anteriormente: la mirada que es vista, la contemplación contemplada. En múltiples ocasiones, la obsesión por la observación atenta se desplaza del objeto mirado al sujeto que mira, a la fuente de la visión. Se presenta entonces, más que una antítesis irresoluble, un encuentro que evoca continuidad, origen constante e infinitud. El poema "El perplejo" dialoga directamente — pareciera ser una continuación — con "Dominio de los sentidos", que se encuentra en La nada (2000), uno de sus primeros poemarios publicados, donde la perplejidad aparece como extrañamiento, como esa conciencia necesaria para captar e iluminar - hacer visible - lo oculto. De hecho, el mismo poema aparece bajo el título "Guía de perplejos de Maimónides", en la versión incluida en El vuelo inmóvil (2004), en referencia explícita al libro del filósofo cordobés.

\title{
Dominio de los sentidos \\ El ojo del ojo: la luz \\ La luz de la luz: la vislumbre \\ La contemplación de la contemplación: \\ la perplejidad (Cadavid, 2000, p. 50).
}

El extrañamiento es entonces, de nuevo, posibilidad de acceder a lo inaccesible. El término "dominio" en el título del poema adquiere así, en una especie de antítesis, la doble alternativa de significación, en tanto poder y espacio de control: solo se puede someter a los sentidos — a la percepción sensorial - en la perplejidad; solo los sentidos alcanzan su pleno dominio — sus plenas posibilidades - cuando son atravesados por el extrañamiento, por la conciencia de aquello que trasciende lo visto al verse. La imagen de la mirada observada se repite de manera explícita en poemas como "Transfiguraciones" o "Parábola sobre la mirada". En todas estas escenas, el ojo opera como la integración entre objeto-sujeto para cerrar una especie de ciclo contemplativo. Desde el punto de vista físico, el ojo es el órgano que recibe la luz; pero, 
en los versos de Cadavid, el ojo no solo la capta, sino que la proyecta para verse a sí mismo "como mira otro"; ya decía Plotino que un ojo no podría ver el sol si no fuera, de alguna manera, semejante al sol (Cirlot, 2016, p. 345). Desde sus inagotables posibilidades simbólicas, la vista y la iluminación se relacionan con conocimiento tanto intelectual como espiritual.

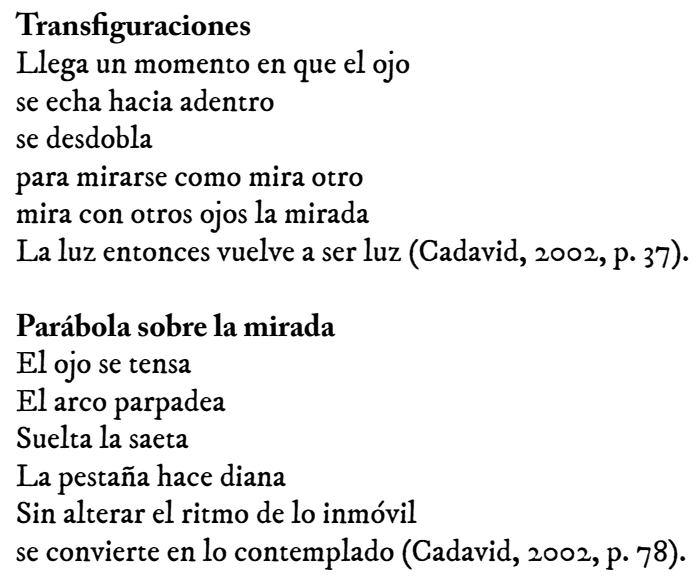

En ambos poemas, el ojo que comienza como sujeto termina como objeto de su propia acción: un mirar(se) que pareciera darse en dos planos distintos: el primero, interior (sin desplazamiento); el segundo, exterior, con el movimiento sugerido por la imagen del arco que dispara y la estela que traza la parábola, término que alude también a un relato que revela la verdad del mirar. Ver aquello - la fuente- que está llevando a cabo el acto de ver no sería otra cosa que la posibilidad de verlo todo.

En diversos momentos de su obra ensayística y poética, Cadavid se refiere a la figura de Miguel de Molinos, creador del quietismo. De hecho, afirma Valente (2000) que los elementos centrales de la Guía espiritual de Miguel de Molinos son el primado de la contemplación, la cesación de los medios y la doctrina de la nada (p. 116), asuntos sobre los que reflexiona de manera permanente la obra de Cadavid. Entre los textos que este último dedica a Miguel de Molinos se encuentran el ensayo "Miguel de Molinos: del Quietismo como magisterio”, y los poemas “Guía espiritual” y “Guía espiritual de Miguel de Molinos". 7 De igual forma, podría incluirse en este listado

"Guía espiritual de Miguel de Molinos" es el nombre completo que aparece en el libro El vuelo inmóvil (2004). El mismo poema aparecía ya en Un leve mandamiento (2002), titulado como "Guía espiritual”, con la dedicatoria a Miguel de Molinos. 
el poema "Del quietismo", que hace parte del libro Tratado de cielo para poetas jóvenes (2008), donde se asiste a la contemplación de una interminable continuidad heraclítea que se revela, finalmente, como quietud:

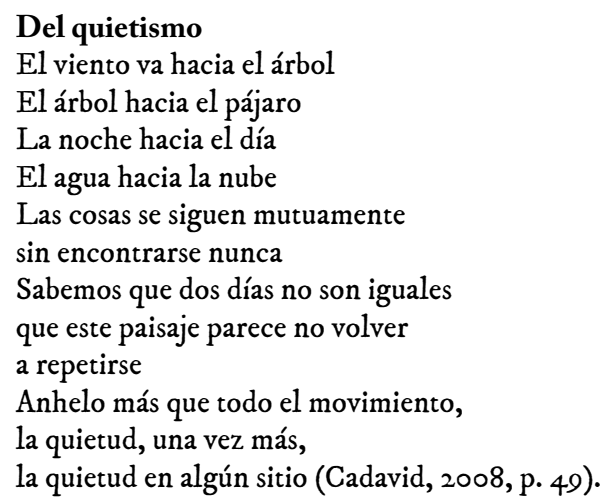

La idea de movimiento último como quietud alberga otro de los rasgos característicos de lo místico: la coincidentia oppositorum, idea que, como indica Velasco (2003), fue formulada por Nicolás de Cusa como única posibilidad del hombre de acceder "al Dios que está en un orden de realidad que excede aquel en el que nuestro pensamiento discurre, recurriendo a conceptos contrarios" (p. 56). La antítesis planteada como continuidad trasciende entonces la limitada dialéctica conceptual y ubica al lector frente a una coexistencia posible, frente a una total apertura, un infinito. Se trata, además, de la "sublime paradoja" (Underhill, 2006, p. 56) entre el ser y el devenir: el movimiento del verso 10 es la misma quietud —el movimiento, "una vez más"— de los versos 11 y 12. La ausencia de la coma antes del "más", que haría de la frase "más que todo el movimiento" un inciso explicativo, abre la ambigüedad que convierte el anhelo de movimiento en quietud. Dicha imagen, en apariencia contradictoria, se resolverá de manera contundente en el último verso del poema "Movimiento": "El movimiento final es la quietud" (Cadavid, 2006, p. 68).

Al reflexionar sobre esta oposición entre ser y devenir, Underhill (2006) menciona el vitalismo filosófico de Heráclito — a quien denomina como "el más místico de los filósofos"- y dice de él que fue capaz de percibir una "oculta unidad por debajo del conflicto, que trascendía todos los puestos creados y enseñó a sus discípulos que 'Habiendo escuchado no a mí, sino al Logos, es prudente confesar que todas las cosas son uno"' (p. 52). Justamente, el nombre de Heráclito aparece mencionado en 
diversos pasajes de la obra de Cadavid, como en el poema "Heráclito inasible" — que da título a uno de sus libros, publicado en 2010 - o en el poema en prosa "Heráclito", de El bosque desnudo (2013), que alberga la misma idea conciliadora de quietud y movimiento: "La fijeza es un pez que vuela" (Cadavid, 2013, p. 62). La misma idea toma mayor fuerza en otro poema titulado "Heráclito", de La nada (2000), donde las dos posiciones se funden literalmente en la eternidad: "Si el ahora del río que pasa hace el tiempo / el ahora del mar que permanece hace la eternidad" (Cadavid, 2000, p. 46).

Imágenes de este tipo — que se suman claramente a las de la contemplación contemplada - se encuentran también en poemas como "Sufí" y en otro poema titulado también "El perplejo", que hace parte del mencionado poemario Heráclito inasible (2010), libro para el cual Cadavid (2010) toma como epígrafe la reconocida contradicción del filósofo presocrático: "El camino ascendente y descendente es el mismo. La misma cosa es y no es" (p. 11).

\author{
El perplejo \\ Las palabras centellantes \\ serán nuestras pupilas \\ Haber borrado todo \\ es haberlo visto todo (Cadavid, 2010, p. 33).
}

Aquí, los pares palabra-imagen y borrar-ver conforman la tensión tranquilizadora sobre la que se posa — reposa - el poema: la oposición no excluye ni anula, sino que abre un espacio de co-existencia: despierta, en palabras de Velasco (2003), una nueva forma de conocimiento (p. 55). La perplejidad — nuevamente, el extrañamientootorga a la palabra la posibilidad de devenir "pupila”; es decir, de ver. Asimismo, es ese estado el que permite borrar para ver: un ver que no es parcial, como cualquier mirada, sino total.

La reflexión sobre contemplación, mirada y quietud se presenta también en "Desde la quietud", aunque más desde lo discursivo, por tratarse de un poema en prosa. Si en "Del quietismo" se observa y se experimenta el paisaje de la inmovilidad, en "Desde la quietud" se expone por qué el hombre contemporáneo estaría poco disversos de este poema los que con mayor claridad remiten a una apertura a la totalidad: toda posibilidad está incluida en esa oposición, que se intensifica con la conjunción copulativa. 
puesto al autoabandono que deriva de la contemplación interior. Se trata del horror vacui. ${ }^{9}$ Para salir de sí mismo (éxtasis), hay que mirarse a sí mismo y hay que dejarse a sí mismo: acciones que no tienen cabida en la sobreabundancia informativa y el ritmo de la actualidad:

Nada tan incómodo para el hombre como estar en reposo absoluto. Intenta leer y no puede, quiere contemplar el paisaje pero siente un callo en sus ojos. Entonces experimenta su nada, su insuficiencia. Porque así, inmóvil, puesto a contemplar su paisaje interior - su alma-, el hombre no soporta la quietud. Por medio de esa nada ha de morir en sí mismo de muchas maneras. Pocos soportan hoy la detención, ese límite entre la aniquilación y el éxtasis (Cadavid, 2013, p. 13).

La contemplación en Cadavid adquiere entonces, como el imperativo wittgensteiniano frente al silencio, cierta dimensión ética que clama por "desacostumbrar la mirada: 'observar el dorso nunca visto del objeto de siempre', ver relaciones en lo más cotidiano; donde nadie atisba supuestamente nada” (Cadavid, 2013, p. 7). Solo la palabra poética, como esa "pupila" de "El perplejo", en su capacidad de distanciarse de la imposición del significado y de abrir las posibilidades denotativas del lenguaje, puede acceder a ese revés nunca contemplado; y recurro aquí no solo a la posibilidad ya discutida del término - la relacionada con la mirada atenta - sino a aquella que alude al tener presente.

\section{Notas finales}

La conciencia sobre la imagen y el silencio se configura en la obra de Cadavid como alternativa frente a las limitaciones del lenguaje discursivo para acceder a determinadas realidades. Contemplar la mirada y escribir el silencio son recursos, contradictorios, que entran en plena sintonía con los caminos que diversas tradiciones religiosas y seculares han empleado para dar cuenta de las experiencias que escapan al entendimiento de la lógica racional y que pueden ser cobijadas por el término "mística". Por medio de ellos, Jorge Cadavid construye una poesía que, desde el lenguaje refrenado, contenido, y desde la disolución del yo, alberga en los versos mismos la verbalización de unión con lo trascendente, aspiración que se concreta en la paradójica fijeza a la que alude el título "Epitafio", tal vez el poema donde lo etéreo se hace más tangible: como las de un estado excepcional, el paso de un umbral, la salida de sí y la mirada: "Bebió azogue / atravesó el espejo desolado / Fuera de sus límites / en su clara invisibilidad / miró pasar las nubes”(Cadavid, 2004, p. 50). 
"Disuelto estás al fin / ceniza soplada por el viento / Fluyes sin forma / del centro a la periferia / sin límites que te marginen/ de lo abierto / Fluyes perfecto / Polvo sin presencia" (Cadavid, 2002, p. 33). Es esta la centralidad des-centrada: la totalidad.

Bajo los dos fenómenos estudiados —así como otros apenas enunciados—, la obra de Cadavid se inscribe en las posibilidades de una palabra que amplía el alcance de lo que la tradición ha entendido bajo la idea de lo místico, comúnmente vinculada con las doctrinas dominantes, y abre nuevos caminos para la aproximación al misterio desde el lenguaje poético. De igual forma, la perspectiva aquí abordada aporta elementos conceptuales y analíticos para la aproximación a la manera en que diversas voces de la poesía colombiana han entablado el diálogo entre poesía y mística, relación que, más allá de nombres canónicos como los de Antonio Llanos, Carlos Obregón o David Mejía Velilla, aún ha sido poco estudiada en el contexto colombiano.

\section{Referencias bibliográficas}

Cadavid, J. (2000). La nada. Medellín: Editorial Universidad de Antioquia.

Cadavid, J. (2002). Un leve mandamiento. Bogotá: Trilce Editores.

Cadavid, J. (2004). El vuelo inmóvil. Bogotá: Universidad Nacional de Colombia.

Cadavid, J. (2008). Tratado de cielo para jóvenes poetas. Medellín: Editorial Universidad de Antioquia.

Cadavid, J. (2009). El lenguaje de la poesía. Entre la analogía y el refrenamiento. Revista Universidad de Antioquia. 295, pp. 94-96.

Cadavid, J. (2010). Heráclito inasible. Bogotá: Editorial Pontificia Universidad Javeriana.

Cadavid, J. (2011). Los ojos deseados. Bogotá: Común Presencia Editores.

Cadavid, J. (2013). El bosque desnudo. Bogotá: Común Presencia Editores.

Cadavid, J. (2015). Pequeña historia de la fotografía. Bogotá: Común Presencia Editores.

Cadavid, J. (2016). La poesía silente. Boletín Cultural y Bibliográfico 50 (90), pp. 236 - 237. Recuperado de https://publicaciones.banrepcultural.org/index.php/boletin cultural/article/view/7642

Certeau de, M. (2006). La fábula mistica (siglos XVI-XVII). Madrid: Ediciones Siruela.

Cirlot, J. E. (2016). Diccionario de símbolos. Madrid: Ediciones Siruela.

Corominas, J. (1987). Breve diccionario etimológico de la lengua castellana. Madrid: Editorial Gredos.

De la Cruz, J. (2010). Obra completa. Tomo 1. Madrid: Alianza Editorial.

Gómez Rincón, C. M. (2015). Experiencia mística, lenguaje y conocimiento. En Á. Uribe Botero y C. M. Gómez Rincón (Eds.). Misticismo y filosofía (pp. 9-30). Bogotá: Editorial Universidad del Rosario. 
Granja Hidrobo, D. (2018). Mística y poesía: una aproximación a la obra de Carlos Obregón (1929-1963). Estudios de Literatura Colombiana 42, pp. 46-61. DOI: https://doi.org/10.17533/udea.elc.n42a03 James, W. (1994). Las variedades de la experiencia religiosa. Ediciones Península. Labraña, M. (2017). Ensayos sobre el silencio. Gestos, mapas y colores. Madrid: Ediciones Siruela. Le Breton, D. (2016). El silencio. Aproximaciones. Madrid: Ediciones Sequitur.

Martínez, G. (2002). La visión de lo indecible. En J. Cadavid. Un leve mandamiento (pp. 11-14). Bogotá: Trilce Editores.

Ong,W. (2009). Oralidad y escritura: tecnologías de la palabra. México, D.F.: Fondo de Cultura Económica. Pérez Parejo, R. (2013). Qué es silencio y qué no es silencio. Claves de una poética. En C. J. Bischoff y A. Thiem (Eds.). Poesía y silencio. Paradigmas hispánicos del siglo XX y XXI (pp. 25-39). Berlín: LIT. Sosa López, E. (1954). Poesía y mistica. Buenos Aires: Editorial Sudamericana.

Soto Posada, G. (2013). Diez místicos medievales. Medellín: Editorial Universidad Pontificia Bolivariana. Toro Murillo, A. y Clavijo Tavera, D. (2020). Pluralidades de un diálogo trascendente: desplazamientos de la poesía mística en Colombia. Literatura: teoría, historia, crítica 22 (2), pp. 271-296.

Underhill, E. (2006). La mistica. Estudio de la naturaleza y desarrollo de la conciencia espiritual. Madrid: Editorial Trotta.

Valente, J. A. (2000). Variaciones sobre el pájaro y la red. Barcelona: Tusquets.

Velasco, J. M. (2003). El fenómeno místico. Madrid: Editorial Trotta.

Villoro, L. (2016). La significación del silencio y otros ensayos. México D.F.: Fondo de Cultura Económica. Wittgenstein, L. (2013). Tractatus lógico-philosophicus. Madrid: Editorial Tecnos. 